\title{
Biosynthesis of Deoxynivalenol in Spikelets of Barley Inoculated with Macroconidia of Fusarium graminearum
}

\author{
C. K. Evans and W. Xie, Research Associates, R. Dill-Macky, Assistant Professor, and C. J. Mirocha, Professor \\ Emeritus, Department of Plant Pathology, University of Minnesota, St. Paul, MN 55108
}

\begin{abstract}
Evans, C. K., Xie, W., Dill-Macky, R., and Mirocha, C. J. 2000. Biosynthesis of deoxynivalenol in spikelets of barley inoculated with macroconidia of Fusarium graminearum. Plant Dis. 84:654-660.

This research examined the biosynthesis of deoxynivalenol (DON) and 15-acetyldeoxynivalenol (15-ADON) in barley spikelets inoculated with macroconidia of Fusarium graminearum (Group-II). Investigations were conducted to determine if these toxins were present in macroconidia of the pathogen prior to inoculating barley spikelets. Extracts of macroconidia cultured from mung bean agar were analyzed using gas chromatography-mass spectrometry. Neither DON or $15-\mathrm{ADON}$ was detected in three isolates' macroconidia when compared with macroconidia-DON-matrix standards adjusted to $100,200,300$, and $400 \mathrm{ng} / \mathrm{g}$ with a detection limit of $100 \mathrm{ng} / \mathrm{g}$. Mean recovery of DON that was added to macroconidia was $89.5 \%$. The same isolates were pathogenic on barley cultivars Robust (moderately susceptible) and Chevron (moderately resistant) and produced DON (0 to $3.69 \mathrm{ng} / \mathrm{g}$ ) and 15-ADON (detected but not quantified) when grown in rice culture. Greenhouse experiments were performed to determine when DON and 15-ADON were detectable after inoculation and to quantify their amount in inoculated barley spikelets. The three isolates of $F$. graminearum were separately inoculated to a central spikelet on heads of barley cultivars Robust and Chevron. Both toxins were detected in spikelets $48 \mathrm{~h}$ postinoculation (PI). DON increased dramatically after $72 \mathrm{~h}$ and did not diminish thereafter. Accumulation of 15-ADON peaked at 72 to $120 \mathrm{~h}$ and decreased by $240 \mathrm{~h}$ PI. There were no statistical differences between cultivars or among fungal isolates for accumulation of either toxin when averaged over the time intervals. Differences of toxin accumulation at each sampling interval were significant $(P<0.0001)$ when averaged over isolates and cultivars. Spikelets of six cultivars and lines were sampled at inoculation and 18, 36, 54, 72, and $90 \mathrm{~h} \mathrm{PI}$. DON and 15-ADON were detected at $36 \mathrm{~h}$ PI, but differences among the cultivars and lines were not significant. Yield of DON in inoculated spikelets of 31 barley cultivars and lines at 72 h PI ranged from 0.14 to $1.26 \mu \mathrm{g}$ per spikelet, and differences among the cultivars and lines were significant $(P<0.002)$. The data demonstrate a useful range of variability for toxin accumulation in inoculated spikelets among germ plasm in the Minnesota breeding program. Macroconidia with no detectable DON or 15-ADON could be used for in vitro studies of toxin biosynthesis. Establishing when DON and 15-ADON are synthesized facilitates studying the effects of promising fungicides, biocontrol organisms, and new or novel genetic resistance mechanisms and if or how they may prevent or delay the biosynthesis of toxins.
\end{abstract}

Fusarium graminearum Schwabe (teleomorph = Gibberella zeae (Schwein.) Petch.) is pathogenic on cereal species, such as wheat (Triticum aestivum L.) and barley (Hordeum vulgare L.), causing Fusarium head blight (FHB) or scab. The pathogen can reduce yield and quality of grain (20) and produces trichothecene mycotoxins such as deoxynivalenol (DON) during parasitic and saprophytic metabo-

Corresponding author: C. K. Evans

E-mail: conkent@puccini.cdl.umn.edu

Published as paper 991220087 of the contribution series of the Minnesota Agricultural Experiment Station based on research conducted under project 22-52.

Accepted for publication 29 February 2000.

Publication no. D-2000-0323-02R

(C) 2000 The American Phytopathological Society lism in host tissues $(15,18)$. In planta experiments demonstrated that DON is phytotoxic to wheat tissues (26). Adams and Hart (2) suggested that DON serves no role as a pathogenicity or virulence factor for $F$. graminearum causing Fusarium ear rot on maize (Zea mays L.). However, Atanassov et al. (3) found that isolates of $F$. graminearum that produced more DON were more aggressive on wheat by reducing grain weights more than isolates that produced less of the toxin in planta.

Desjardins et al. (7) developed mutant isolates of $F$. graminearum that could no longer produce trichodiene synthase, the enzyme that catalyzes the first step in the trichothecene biosynthesis pathway. The mutant isolates were pathogenic on wheat, although they no longer produced any trichothecene toxins. The mutant isolates did not cause symptoms as severe or reduce seed viability and seed weight of the host when compared with the original wild-type isolates that produced trichothecenes. The published literature suggests that the inability to produce trichothecenes does not prevent the pathogenicity of $F$. graminearum, but the toxins may serve as aggressiveness or virulence factors for the pathogen. Previous investigations of trichothecene toxins produced by $F$. graminearum have assessed their initial occurrence between 8 and 14 days postinoculation (PI) $(13,14)$. Other investigations of $F$. graminearum determined the quantity of trichothecene(s) in grain or plant tissues after grain harvest $(7,15,17,28)$ or did not specify the precise time between inoculation and toxin quantification (24).

Our objective was to determine when trichothecenes, specifically DON and 15ADON, are produced by $F$. graminearum in the first and second days of infection of barley. Understanding when biosynthesis of DON and other trichothecenes occurs in planta may lead to a better understanding of the function of these toxins in the development of FHB. Additionally, we investigated whether isolates of $F$. graminearum differed in production of DON and 15ADON during infection of barley. Finally, we investigated the range of reaction for DON and 15-ADON accumulation among selected lines and cultivars of barley currently being utilized in crosses in the Minnesota breeding program. Previous research demonstrated that several fungi produce mycotoxins that are present within or on the surface of their respective spores $(10,25,27)$. Hence, we needed to develop a technique that would enable us to generate large quantities of macroconidia of $F$. graminearum having no detectable DON or $15-\mathrm{ADON}$ in or on them. This paper describes such a technique using three isolates of $F$. graminearum.

\section{MATERIALS AND METHODS}

Isolate collection and production of macroconidia for toxin analyses. Three isolates of $F$. graminearum were obtained from symptomatic spikes of wheat and barley from separate geographic locations within the Red River Valley of Minnesota during the summer of 1995 . Isolate Butte86ADA-11 was cultured from wheat. Isolates M66ADA-B1-A1 and 3A-31 were cultured from barley. Isolations were made according to the procedures of Wilcoxson et al. (28). Our identification of the isolates of $F$. graminearum (teleomorph $=$ Gibberella zeae) followed the descriptions of 
Nelson et al. (19) and Burgess et al. (5) for group-II isolate characteristics.

In all tests, macroconidia of the three isolates of $F$. graminearum were produced by culture on mung bean agar (MBA: $40 \mathrm{~g}$ of mung bean [var. Berken Improved]/liter, placed in boiling distilled water for $23 \mathrm{~min}$ [ $\sim 50 \%$ of seed pericarps split while cooking] filtered through two layers of cheesecloth, adjusted to 1 liter, $15 \mathrm{~g}$ of agar). Isolates were initially cultured on potato dextrose agar (PDA), and after about 7 days, hyphae from the margin of the fungal colony were transferred to petri plates of MBA. The three isolates were inoculated separately onto the surface of MBA by adding $1 \mathrm{ml}$ of previously prepared macroconidial inoculum ( 1 to $5 \times 10^{5}$ per $\mathrm{ml}$, obtained from MBA inoculated with hyphal tuft). Macroconidia were spread over the surface of the medium using a sterile bent-glass rod. Cultures were grown on lab benches under fluorescent lights (12:12 light:dark, $\left.36 \mu \mathrm{mol} \cdot \mathrm{m}^{-2} \cdot \mathrm{s}^{-1}\right)$ at room temperature $\left(20\right.$ to $22^{\circ} \mathrm{C}$ ) for 14 days. On day 14, macroconidia of each isolate were washed from the surface of the MBA using a Solo hand-sprayer (Model 454, Hummert Intl., Earth City, MO) with about 10 to 20 $\mathrm{ml}$ of distilled water per petri dish (8). The suspension of spores and mycelial fragments was filtered through one layer of cheesecloth, and spore concentrations were determined using a hemacytometer. Total volume of the spore suspension was also measured. For each isolate, the spore suspension was centrifuged at $\sim 2,200 \mathrm{rpm}$ for $10 \mathrm{~min}$. The supernatant suspension was removed, and the resulting pellet of macroconidia of $F$. graminearum was weighed (fresh weight) and stored at $-20^{\circ} \mathrm{C}$ for later extraction, detection, and quantification of DON. The spore concentrations of the supernatant suspensions were also measured to correct the estimate of the number of spores harvested.

Analysis of macroconidia for DON sample extraction. Macroconidia pellets obtained from the three isolates of $F$. graminearum in centrifuge tubes were vacuum-dried at $-1.9 \times 10^{5} \mathrm{~Pa}$ for $22 \mathrm{~h}$ at $23^{\circ} \mathrm{C}$. Four $100-\mathrm{mg}$ samples of dried macroconidia of each isolate were extracted with $1.5 \mathrm{ml}$ of acetonitrile:water $(86: 24$, $\mathrm{vol} / \mathrm{vol})$ in a 1-dram vial $(4 \mathrm{ml})$ for $24 \mathrm{~h}$. The extract was partially purified by passing it through a mini-column $(0.15 \mathrm{~g}$ $\mathrm{C}_{18}$ :Alumina [1:3 wt/wt] in a $1-\mathrm{ml}$ tuberculin syringe). One milliliter of the partially purified extract was transferred to a 0.5 -dram $(2 \mathrm{ml})$ vial and evaporated to dryness under nitrogen and was ready for derivatization.

Preparation of DON standards in macroconidia-matrices. The matrices were prepared by extracting vacuum-dried macroconidia by the procedure described above. DON standards at concentrations of 100, 200, 300, and 400 parts per billion (ng/g) were prepared by adding 6.7, 13.3,
20.0, and $26.7 \mathrm{ng}$ (in a $1 \mathrm{ng} / \mu \mathrm{l}$ standard solution) to $1 \mathrm{ml}$ of matrix extract $(66.7$ mg equivalent of macroconidia), respectively. The extracts were then evaporated to dryness.

Preparation of macroconidia by adding known amounts of DON (spiking). Four 100-mg samples of vacuum-dried macroconidia (isolate Butte86ADA-11) in separate 1-dram vials were spiked with DON to $100,200,300$, and $400 \mathrm{ng} / \mathrm{g}$ by adding $10,20,30$, and $40 \mu \mathrm{l}$ of standard solution $(1 \mathrm{ng} / \mu \mathrm{l})$, respectively. The solvent was evaporated under nitrogen. The DONspiked spores were extracted by the above procedure.

Analyses of macroconidia-matrix standards and DON-spiked macroconidia for toxin recovery. Samples were derivatized with $20 \mu \mathrm{l}$ of $N$-trimethylsilyl imidazole (TMSI)-trimethylchlorosilane (TMCS) (100:1 vol/vol). Isoöctane $(180 \mu \mathrm{l})$ was added, followed by $180 \mu \mathrm{l}$ of water to quench the reaction. Vials were shaken using a vortex mixer until the upper layer (organic phase) became clear. The organic phase was transferred to 200- $\mu$ l sample inserts and analyzed by injecting a 1- $\mu \mathrm{l}$ aliquot into a Shimadzu QP-5000 gas chromatography-mass spectrometer (GC/MS) for quantification. The mass spectrometer was operated in selected ion monitoring mode. Ions at $\mathrm{m} / \mathrm{z}$ 422, 407, and 392 were monitored. A 4-point standard curve was generated from the matrix extracts and used for DON quantification of spikedmacroconidia samples and detection and quantification of nonspiked macroconidia samples.

Analysis of DON in residual wash-water and MBA. Analyses for the presence of DON in the MBA and wash-water used to remove the macroconidia from the medium were made for each fungal isolate. Twenty milliliters of wash-water was filtered through a 0.2- $\mu \mathrm{m}$ filter (Sterile Acrodisc 13, Gelman Sciences, Ann Arbor, MI) to remove fungal debris and culture medium. Aliquots $(15 \mathrm{ml}$ per isolate plus a prewash water control) were transferred to 20-ml scintillation vials, dried under air for $24 \mathrm{~h}$, and capped for DON detection analyses at a later date.

After macroconidia were harvested, one agar plug was removed from each petri dish culture of MBA (10 per isolate $=10$ plugs, $3 \mathrm{~mm}$ diameter; plugs were also taken from a noninoculated MBA petri dish [control] for comparison) using a cork borer. Agar plugs of isolate cultures were stored separately at $-20^{\circ} \mathrm{C}$ for later detection and quantification of DON.

MBA plugs were weighed. Acetonitrile:water (84:16 volume ratio) was added $(1.5 \mathrm{ml})$ to MBA agar plugs and washwater residue samples in 20-ml scintillation vials. The MBA samples were then placed on a shaker for $24 \mathrm{~h}$. The washwater samples were not shaken. The $1.5-\mathrm{ml}$ samples were then passed through mini- columns and collected in test tubes $(15 \times$ $85 \mathrm{~mm})$. One-milliliter aliquots were removed and dried under nitrogen in 0.5dram vials. Samples were then derivatized with $20 \mu \mathrm{l}$ of a mixture of TMSI:TMCS (100:1 vol/vol). After TMSI:TMCS was added, samples were gently mixed with a vortex mixer and rotated by hand to ensure reaction with the residue on the sides of the vials. Samples were left on lab benches for $15 \mathrm{~min}$, and $30 \mu \mathrm{l}$ of isoöctane was added per sample. A 1- $\mu$ l aliquot was removed per sample and manually injected into the GC/MS to quantify DON. Macroconidia, MBA plugs, and wash-water samples were assayed for detection and quantification of DON four separate times.

In vitro verification of $\mathrm{DON}$ production and pathogenicity of $F$. graminearum isolates. In vitro verification of DON production was performed by culturing the three isolates on rice and analyzing the culture extracts in three tests (one replicate per isolate per test) following the descriptions of Abbas et al. (1). Rice medium was prepared by weighing $200 \mathrm{~g}$ of white rice into 10 1-liter Erlenmeyer flasks containing $125 \mathrm{ml}$ of double distilled water. After $2 \mathrm{~h}$, the flasks were autoclaved for $20 \mathrm{~min}$ and removed to lab benches for $24 \mathrm{~h}$. One flask of rice medium was utilized as a noninoculated control. Each isolate of $F$. graminearum was inoculated to the rice by cutting a 3-mmdiameter agar plug from cultures of $F$. graminearum that were maintained on PDA. Rice cultures were grown for 30 days with supplemental lighting (12:12 light:dark, 5,300 lx) at room temperature ( 21 to $25^{\circ} \mathrm{C}$ in two tests and 13 to $16^{\circ} \mathrm{C}$ in a third test), then removed and dried in a fume hood for 5 days. The dried rice cultures were ground, extracted, and analyzed for DON using a Shimadzu QP-5000 GC/MS following the procedures of Mirocha et al. (17) for batch analyses of samples.

Pathogenicity of isolates of $F$. graminearum and in planta verification of DON production. Barley cultivars Robust (moderately susceptible) and Chevron (moderately resistant) (18) were planted in plastic pots $(13 \times 13 \mathrm{~cm}$, diameter $\times$ height) containing Metro-Mix 200 growth medium (Scotts-Sierra Horticultural Products, Marysville, $\mathrm{OH})$. Pots were planted with three seeds per pot and thinned to one plant when seedlings were at the three-leaf stage. Each potted seedling was fertilized with $3 \mathrm{~g}$ of slow-release 14-14-14 (N-P-K) fertilizer. Temperatures in the greenhouse throughout the test ranged from 20 to $25^{\circ} \mathrm{C}$.

Macroconidia were produced by culturing the isolates of $F$. graminearum on MBA in petri plates. Isolates were grown for 14 days, and macroconidia were harvested by adding $10 \mathrm{ml}$ of sterile distilled water to each plate. Macroconidia were dislodged by gently stirring the flooded 
culture with a sterile bent-glass rod. Inoculum suspensions were subsequently removed with a micropipette. Inoculum concentrations were adjusted to $2.0 \times 10^{5}$ macroconidia per $\mathrm{ml}$. Plants were inoculated at Zadoks' growth stage 71 (29), approximately 37 days after planting. The central floret from a central node per head of the six-row or two-row cultivars was inoculated. This was done to standardize the inoculated spikelet position in the barley heads. The base of the awn on the inoculated spikelet was marked for identification purposes. The spikelet was carefully opened by spreading the palea and lemma and placing $10 \mu \mathrm{l}$ of inoculum within the flower using a syringe. Only the primary head of each plant was inoculated. Two plants (pots) of each cultivar were inoculated with each isolate, and a further two plants were used as water-inoculated controls. Inoculated plants were placed in a dew chamber providing approximately $98 \%$ relative humidity for $72 \mathrm{~h}$. Continuous lighting was provided with two 40watt fluorescent lights $\left(6 \mu \mathrm{mol} \cdot \mathrm{m}^{-2} \cdot \mathrm{s}^{-1}\right)$ during the dew period. Plants were then removed to greenhouse benches. Viability estimates of macroconidia of the three isolates of $F$. graminearum were made by separately inoculating water agar in petri dishes $(15 \times 100 \mathrm{~mm})$ and maintaining them on lab benches at 20 to $23^{\circ} \mathrm{C}$ with continuous overhead fluorescent lighting. Germination was estimated by arbitrarily examining 100 spores of each isolate after $6 \mathrm{~h}$.

Inoculated spikelets were removed 23 days postinoculation. Spikelet removal was accomplished using forceps rinsed with acetone after each removal. This was done to minimize trichothecene contamination from one inoculated spikelet to another. Harvested spikelets were placed in cryovials and maintained at $-70^{\circ} \mathrm{C}$ for later extraction and analyses. Harvested spikelets were weighed, then extracted for DON and $15-A D O N$ by soaking the spikelets in 1.5 $\mathrm{ml}$ of acetonitrile:water $(84: 16 \mathrm{vol} / \mathrm{vol})$ for $24 \mathrm{~h}$ on a shaker table following the descriptions of Mirocha et al. (17) for single kernel analyses.

Inoculation of isolates of $F$. graminearum to central spikelets of barley and DON and 15-ADON analyses over six sample time intervals. The first greenhouse experiment was conducted twice to determine the timing of DON and 15ADON production in inoculated spikelets of barley cultivars Chevron and Robust (18). Analyses of single kernel extracts for the detection and quantification of DON and 15-ADON were made following the procedures of Mirocha et al. (17). Each cultivar was inoculated with three isolates of $F$. graminearum separately. The design was a randomized split-split block with three replicates. Time intervals were designated as main plot treatments with cultivars as subplot treatments and isolates of $F$. graminearum as sub-subplot treatments. The cultivars were planted in plastic pots $(13 \times 13 \mathrm{~cm}$, diameter and height $)$ containing Metro-Mix 200 growth medium. Five seeds were planted per pot, and plants were thinned to three when seedlings were at the three-leaf growth stage. Three replicates were used, with the primary head of each plant representing one replicate (three replicates per pot). Each pot was fertilized with $3 \mathrm{~g}$ of slow-release 14-14-14 (N-P-K) fertilizer. Three plants of each cultivar (one pot of each at a sample time) were used as water-inoculated controls. Temperatures in

Table 1. Analyses of variance of barley cultivars Robust and Chevron in a split-split-block design for deoxynivalenol (DON) and 15-acetyldeoxynivalenol (15-ADON) ( $\mu \mathrm{g}$ per spikelet) produced by three Fusarium graminearum isolates in inoculated spikelets sampled at 24-h intervals over 3 days and at 120 and $240 \mathrm{~h}$ postinoculation in tests of the first greenhouse experiment

\begin{tabular}{|c|c|c|c|c|c|}
\hline \multirow[b]{2}{*}{ Model } & \multirow[b]{2}{*}{ df } & \multicolumn{2}{|c|}{ DON } & \multicolumn{2}{|c|}{ 15-ADON } \\
\hline & & $\begin{array}{c}\text { Mean } \\
\text { square }\end{array}$ & $P>F$ & $\begin{array}{c}\text { Mean } \\
\text { square }\end{array}$ & $P>F$ \\
\hline Test (A) & 1 & 0.078 & 0.85 & 0.109 & 0.44 \\
\hline Replicate & 2 & 1.067 & 0.64 & 0.030 & 0.79 \\
\hline Error A & 2 & 1.910 & 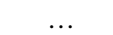 & 0.120 & \\
\hline Time interval (B) & 5 & 57.923 & $<0.0001$ & 3.508 & $<0.0001$ \\
\hline $\mathrm{A} \times \mathrm{B}$ & 5 & 5.127 & 0.001 & 0.284 & 0.03 \\
\hline Error B & 20 & 0.856 & $\ldots$ & 0.097 & $\ldots$ \\
\hline Host cultivar (C) & 1 & 0.320 & 0.59 & 0.028 & 0.61 \\
\hline $\mathrm{A} \times \mathrm{C}$ & 1 & 4.007 & 0.07 & 0.054 & 0.49 \\
\hline $\mathrm{B} \times \mathrm{C}$ & 5 & 2.424 & 0.09 & 0.022 & 0.95 \\
\hline $\mathrm{A} \times \mathrm{B} \times \mathrm{C}$ & 5 & 1.913 & 0.17 & 0.532 & 0.003 \\
\hline Error $\mathrm{C}$ & 24 & 1.134 & $\ldots$ & 0.111 & . \\
\hline F. graminearum isolate (D) & 2 & 1.144 & 0.27 & 0.050 & 0.57 \\
\hline$A \times D$ & 2 & 0.789 & 0.40 & 0.035 & 0.67 \\
\hline$B \times D$ & 10 & 0.821 & 0.49 & 0.087 & 0.45 \\
\hline $\mathrm{C} \times \mathrm{D}$ & 2 & 2.258 & 0.07 & 0.097 & 0.33 \\
\hline $\mathrm{A} \times \mathrm{B} \times \mathrm{D}$ & 10 & 1.276 & 0.16 & 0.045 & 0.87 \\
\hline$A \times C \times D$ & 2 & 1.422 & 0.19 & 0.044 & 0.61 \\
\hline $\mathrm{B} \times \mathrm{C} \times \mathrm{D}$ & 10 & 1.595 & 0.06 & 0.069 & 0.64 \\
\hline $\mathrm{A} \times \mathrm{B} \times \mathrm{C} \times \mathrm{D}$ & 10 & 0.879 & 0.43 & 0.092 & 0.40 \\
\hline Error D & 96 & 0.868 & $\ldots$ & 0.088 & $\ldots$ \\
\hline
\end{tabular}

the greenhouse throughout the tests ranged from 20 to $25^{\circ} \mathrm{C}$. We marked the base of the awn on one central spikelet from the center-node of each head at growth stage 71 (29) to indicate which spikelet was inoculated. The marked spikelet was carefully opened and inoculated by placing 10 $\mu \mathrm{l}$ (containing about 2,000 macroconidia) of inoculum between the lemma and palea. Primary spikes of three plants (replicates) of each cultivar were inoculated for each isolate. Inoculated plants were allowed to stand for $1 \mathrm{~h}$, then placed in a dew chamber providing about $98 \%$ relative humidity and continuous low light $\left(6 \mu \mathrm{mol} \cdot \mathrm{m}^{-2} \cdot \mathrm{s}^{-1}\right)$ at 20 to $22^{\circ} \mathrm{C}$. Sampling time intervals were $0,24,48,72,120$, and $240 \mathrm{~h}$. At each time interval, the central inoculated spikelet was removed with forceps and placed in a small cryovial and frozen at $-70^{\circ} \mathrm{C}$. The forceps were rinsed with acetone after harvesting each inoculated spikelet, as described earlier. Samples at 24 and $48 \mathrm{~h}$ were obtained while the plants were still in the dew chamber. At $72 \mathrm{~h}$, plants were removed from the dew chamber, spikelet samples were removed, and the remaining plants were placed on a greenhouse bench. Inoculated spikelets were later removed from the freezer, weighed, and then kept on ice. Each weighed spikelet was placed in a test tube $(15 \times 85 \mathrm{~mm})$, and $1.5 \mathrm{ml}$ of acetonitrile:water $(84: 16 \mathrm{vol} / \mathrm{vol})$ was added. The spikelet samples were then placed on a shaker for $24 \mathrm{~h}$. All of the 1.5-ml samples were then passed through mini-columns as described earlier. Derivatization and quantification of extracts were the same as described earlier following the procedures of Mirocha et al. (17) for single kernel extraction and analyses of DON and 15ADON. Analyses of variance of yield of DON and 15-ADON in spikelets of barley ( $\mu \mathrm{g}$ per spikelet and $\mu \mathrm{g} / \mathrm{g}$ in spikelets) were made (Table 1) using the ANOVA procedure of SAS (SAS Institute, Cary, NC). Data are presented as mean toxin yield ( $\mu \mathrm{g}$ per spikelet) with standard errors over the sampling intervals (Figs. 1 to 3 ).

The second greenhouse experiment was conducted twice using six lines and cultivars of barley. Temperatures and conditions of the tests were maintained as described previously. Cultivars Robust and Chevron were included as checks from the first greenhouse experiment. The FHBsusceptible cultivar Steptoe was included, as were three lines from the cross $\mathrm{Chev-}$ ron/M69//Stander, designated M95-1, M95-4, and M95-7. Twelve pots of each line or cultivar were planted as described previously. Six plants (pots) were inoculated with the pathogen, and six plants were included as water-inoculated controls. One isolate of $F$. graminearum (Butte86ADA-11) was used to inoculate the plants as described earlier. The experiment design was a randomized split block with three replicates. Time intervals were designated as main-plot treatments and 
lines and cultivars as subplot treatments. Samples were taken at 18 -h intervals postinoculation, beginning at $0 \mathrm{~h}$ and concluding at $90 \mathrm{~h}$. Spikelet sampling, extraction, and quantification of DON and 15ADON were as described previously. At 72 $h$, plants were removed from the dew chamber, spikelet samples were removed, and the remaining plants were returned to the greenhouse until the last sample interval.

The third greenhouse experiment was conducted twice using 31 lines and cultivars of barley. The lines and cultivars of barley tested consisted of a range of material utilized in the Minnesota barley breeding program, including nine two-row barleys. Robust and Chevron were included as checks. Six pots of each line or cultivar were planted as described in the previous greenhouse experiments but were thinned to one plant per pot, and one additional pot was included as a water-inoculated control. Each pot with one plant was considered a replicate. The primary head of each plant was inoculated as described previously. There were five replicates (pots) for each line or cultivar in a completely randomized design. Spikelet inoculation, sampling, extraction, and quantification of DON and 15-ADON were conducted as described previously. The

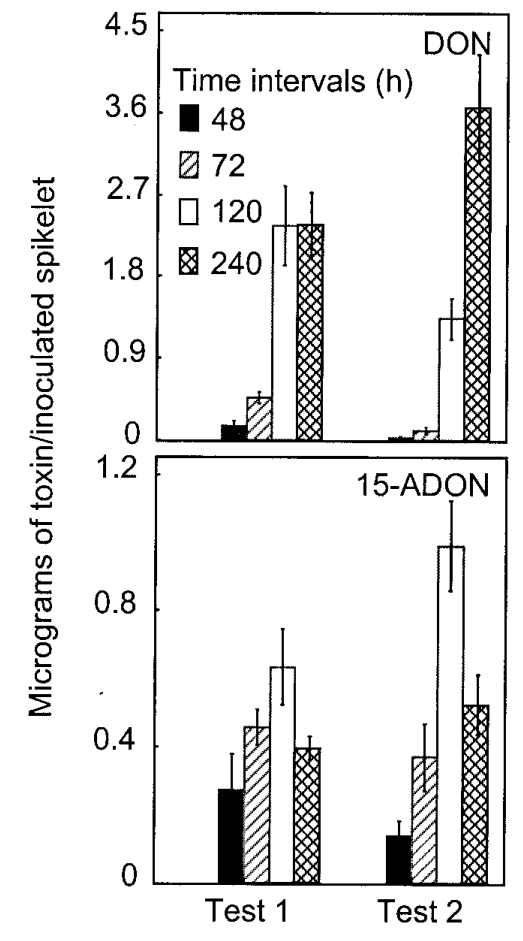

Fig. 1. Mean yield of deoxynivalenol (DON) and 15-acetyldeoxynivalenol (15-ADON) in inoculated spikelets averaged over Robust and Chevron barley cultivars and three isolates of Fusarium graminearum. The two tests of the first greenhouse experiment are presented. Bars indicate standard errors of means. No DON or $15-\mathrm{ADON}$ was detected in inoculated spikelets at 0 or $24 \mathrm{~h}$ postinoculation. inoculated spikelets were sampled $72 \mathrm{~h}$ after inoculation.

\section{RESULTS}

The fresh weight of macroconidia pellets obtained from MBA culture followed by centrifugation was about $4 \mathrm{~g}$ for each isolate. We estimate that there were approximately $1.33 \times 10^{7}$ macroconidia in each of the vacuum-dried samples that we analyzed for the presence of DON. Estimates of the weight of one macrocondium were approximately $750 \mathrm{pg}$ (dried) to $930 \mathrm{pg}$ (fresh weight). The detection limit for the analytical method to quantify DON in macroconidia was $100 \mathrm{ng} / \mathrm{g}$. The recoveries of DON from macroconidia to which DON was added were $76,111,86$, and $85 \%$ at 100, 200, 300, and $400 \mathrm{ng} / \mathrm{g}$, respectively. DON was not detected in the spores, the MBA-culture samples, the wash-water samples, the MBA-control, or the prewash-water control at the $100 \mathrm{ng} / \mathrm{g}$ detection limit. Mass fragments of 15-ADON were not detected in any sample extract.

The nonreplicated tests of in vitro DON production $(+/-)$ in rice culture demon-

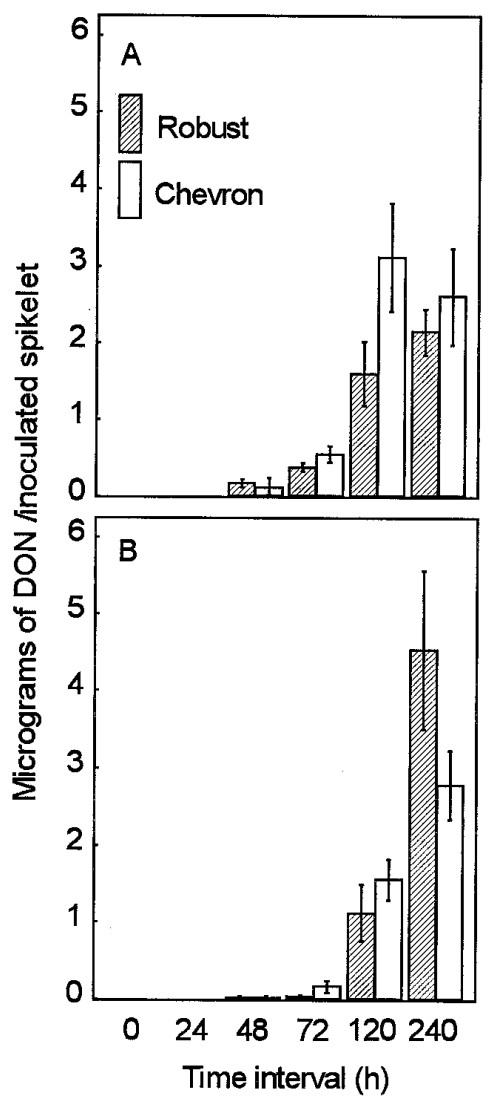

Fig. 2. Mean yield of deoxynivalenol (DON) in inoculated spikelets of barley cultivars Robust and Chevron in two tests (A and B) averaged over three isolates of Fusarium graminearum. Bars indicate standard errors of means. No DON was detected in inoculated spikelets at 0 or $24 \mathrm{~h}$ postinoculation. strated the isolates of $F$. graminearum were capable of producing the toxin. Isolate $3 \mathrm{~A}$ 31 produced DON at 0.23 to $0.56 \mu \mathrm{g} / \mathrm{g}$, and isolates M66ADA-B1-A1 and Butte86ADA11 produced DON at 0.13 to 1.24 and 0 to $3.69 \mu \mathrm{g} / \mathrm{g}$ in rice culture, respectively. The presence of 15-ADON was detected in inoculated rice cultures but was not quantified. DON and 15-ADON were not detected in noninoculated rice culture controls. When inoculated to spikelets of Robust and Chevron in greenhouse pathogenicity tests, isolate 3A-31 produced a mean of $777( \pm 44$, standard deviation) $\mu \mathrm{g}$ of DON per $\mathrm{g}$ in Robust, whereas it did not produce detectable DON in Chevron. Chevron has thin spikelets and possibly escaped infection due to the difficulty inoculating its spikelets. Isolate M66ADAB1-A1 produced means of $244( \pm 301)$ and $227( \pm 305) \mu \mathrm{g}$ of DON per g, and Butte86ADA-11 produced $720( \pm 59)$ and $1090( \pm 56) \mu \mathrm{g}$ of DON per $g$ in Robust and Chevron, respectively. Mass fragments of 15 -ADON were detected, but the amount of toxin was not quantified. No DON was detected in water-inoculated controls of either cultivar. Viability of macroconidia of the three isolates of $F$. graminearum on water agar was always greater than $98 \%$. No mycelial fragments were observed

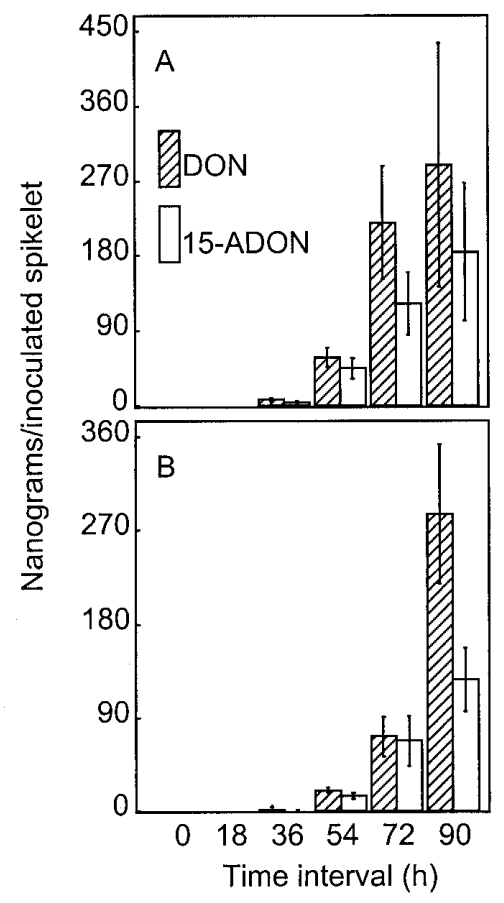

Fig. 3. Mean yield of deoxynivalenol (DON) and 15-acetyldeoxynivalenol (15-ADON) averaged over six lines and cultivars of barley in two tests (A and B). Spikelets of the six barleys were inoculated with isolate Butte86ADA-11 of Fusarium graminearum. Bars indicate standard errors of means. No DON or 15-ADON was detected at 0 or $18 \mathrm{~h}$ postinoculation. 
when spore germination counts were conducted.

In the first greenhouse experiment, significant differences $(P<0.0001)$ among the time intervals for DON and 15-ADON accumulation in both Robust and Chevron (Table 1, Fig. 1) were observed. DON and $15-A D O N$ were first detected in both cultivars at $48 \mathrm{~h}$ (PI) (Fig. 1). There was also a significant experiment by time interval interaction for both DON and 15-ADON accumulation as well (Fig. 1). The interactions of experiment by host cultivar and time interval by host cultivar were significant at $P=0.07$ and $P=0.09$ for DON accumulation, respectively (Fig. 2). Differences between experiments, between Robust and Chevron, and among the three isolates of $F$. graminearum for DON or 15ADON accumulation-production were not significant. However, the experiment by time interval by host cultivar interaction for 15-ADON accumulation was significant at $P=0.003$. The interactions of host cultivar by $F$. graminearum isolate and time interval by host cultivar by $F$. graminearum isolate were significant at $P$ $=0.07$ and $P=0.06$ for DON accumulation, respectively. No DON or $15-\mathrm{ADON}$ was detected in any of the water-inoculated spikelets.

In the second greenhouse experiment involving six cultivars and lines of barley and one isolate of $F$. graminearum, there were significant differences among the time intervals for DON and 15-ADON accumulation (Table 2). DON and 15ADON were first detected $36 \mathrm{~h}$ PI, al- though yield of toxin was low (Fig. 3). There were significant differences between experiments for DON and 15-ADON accumulation $(P=0.006$ and $P=0.01)$, but all interactions were not significant. Neither DON nor 15-ADON was detected in any of the water-inoculated spikelets.

The third greenhouse experiment demonstrated there were significant differences among the 31 barley lines and cultivars for DON and 15-ADON accumulation (Table 3). DON in inoculated spikelets ranged from a high of 1.24 to a low of $0.14 \mu \mathrm{g}$ per spikelet (Table 4). There was no clear relation between the amounts of DON and 15ADON in the inoculated spikelets. There was a significant difference between experiments for the amount of DON in inoculated spikelets of the 31 lines and cultivars tested. Mean DON yields were 0.76 and $0.59 \mu \mathrm{g}$ per spikelet in the first and second greenhouse tests, respectively. There was no significant difference between the two tests for 15-ADON accumulation. DON and 15-ADON were not detected in any of the water-inoculated spikelets of control plants.

\section{DISCUSSION}

The inoculum production technique allowed us to attain high yields of macroconidia of the three isolates of $F$. graminearum that we could concentrate via centrifugation. We estimate there were about $1.33 \times 10^{7}$ macroconidia in the 100 mg samples we analyzed for DON. The comparison of macroconidia-matrices, to which known amounts of DON were added

Table 2. Analyses of variance of six lines and cultivars of barley in a randomized split block design for deoxynivalenol (DON) and 15-acetyldeoxynivalenol (15-ADON) produced by one Fusarium graminearum isolate in inoculated spikelets (ng per spikelet) sampled at 18-h intervals concluding at $90 \mathrm{~h}$ over two tests of the second greenhouse experiment

\begin{tabular}{|c|c|c|c|c|c|}
\hline \multirow[b]{2}{*}{ Model } & \multirow[b]{2}{*}{ df } & \multicolumn{2}{|c|}{ DON } & \multicolumn{2}{|c|}{ 15-ADON } \\
\hline & & Mean square & $P>F$ & Mean square & $P>F$ \\
\hline Test (A) & 1 & 57,007 & 0.006 & 32,191 & 0.01 \\
\hline Replicate & 2 & 8,159 & 0.04 & 21,529 & 0.02 \\
\hline Error A & 2 & 358 & & 542 & \\
\hline Time interval (B) & 5 & 486,158 & $<0.0001$ & 150,179 & $<0.0001$ \\
\hline$A \times B$ & 5 & 30,479 & 0.48 & 6,801 & 0.70 \\
\hline Error B & 20 & 32,903 & & 11,335 & \\
\hline Host cultivar (C) & 5 & 34,682 & 0.64 & 4,006 & 0.93 \\
\hline $\mathrm{A} \times \mathrm{C}$ & 5 & 26,305 & 0.76 & 14,107 & 0.49 \\
\hline $\mathrm{B} \times \mathrm{C}$ & 25 & 60,266 & 0.26 & 15,048 & 0.55 \\
\hline $\mathrm{A} \times \mathrm{B} \times \mathrm{C}$ & 25 & 35,597 & 0.84 & 15,106 & 0.54 \\
\hline Error $\mathrm{C}$ & 120 & 50,903 & $\ldots$ & 16,006 & $\ldots$ \\
\hline
\end{tabular}

Table 3. Analyses of variance of 31 barley cultivars and lines in a completely randomized design for deoxynivalenol (DON) and 15-acetyldeoxynivalenol (15-ADON) ( $\mu$ g per spikelet) in spikelets $72 \mathrm{~h}$ postinoculation over two tests of the third greenhouse experiment

\begin{tabular}{|c|c|c|c|c|c|}
\hline \multirow[b]{2}{*}{ Model } & \multirow[b]{2}{*}{ df } & \multicolumn{2}{|c|}{ DON } & \multicolumn{2}{|c|}{ 15-ADON } \\
\hline & & Mean square & $P>F$ & Mean $^{a}$ square & $P>F$ \\
\hline Cultivar/line (A) & 30 & 1.172 & 0.0005 & 23.646 & 0.0002 \\
\hline Test (B) & 1 & 2.064 & 0.04 & 0.244 & 0.87 \\
\hline $\mathrm{A} \times \mathrm{B}$ & 30 & 0.650 & 0.19 & 13.043 & 0.13 \\
\hline Error & 248 & 0.528 & $\ldots$ & 9.927 & $\ldots$ \\
\hline
\end{tabular}

${ }^{a}$ Numerical values in the column are adjusted by $10^{-2}$.

after extraction of spores, with macroconidia to which DON was added prior to their extraction, showed that DON could be detected in the 100-mg samples to a limit of 100 parts per billion with a mean recovery of $89.5 \%$ from spiked macroconidia. We did not observe any DON in samples of macroconidia where the toxin was not added to the sample. Our results indicate that macroconidia of $F$. graminearum cultured from MBA do not have DON in or on them. Mass fragments of 15-ADON were not detected in the macroconidia extracts. In inoculations of barley with our isolates of $F$. graminearum, we used a small volume $(10 \mu \mathrm{l})$ of inoculum containing about 2,000 macroconidia. Thus, it is unlikely that DON or 15-ADON was introduced to spikelets of barley at the time of inoculation. Amounts of DON and 15-ADON detected in spikelets at the time intervals following inoculation were due to the biochemical activities of $F$. graminearum.

We demonstrated that the three isolates of $F$. graminearum were capable of producing DON and 15-ADON in rice culture. The in planta experiments revealed that the same isolates were pathogenic and were

Table 4. Mean yield of deoxynivalenol (DON) and 15-acetyldeoxynivalenol (15-ADON) in inoculated spikelets of 31 barley cultivars or lines over two greenhouse tests

\begin{tabular}{|c|c|c|}
\hline \multirow[b]{2}{*}{ Cultivar or line $^{a}$} & \multicolumn{2}{|c|}{$\mu \mathrm{g}$ per inoculated spikelet } \\
\hline & DON & 15-ADON \\
\hline Steptoe & 1.24 & 0.19 \\
\hline CI 4196* & 1.21 & 0.43 \\
\hline Svanhals* & 1.17 & 0.38 \\
\hline Excel & 1.13 & 0.32 \\
\hline Zhedar* & 1.06 & 0.41 \\
\hline Horni Peseky* & 1.04 & 0.14 \\
\hline Fredrickson* & 1.02 & 0.26 \\
\hline Mis Cal 21* & 0.98 & 0.10 \\
\hline Gobernadora* & 0.97 & 0.11 \\
\hline MNS 93 & 0.94 & 0.19 \\
\hline Stander & 0.90 & 0.45 \\
\hline Harbin* & 0.89 & 0.70 \\
\hline Kitchin* & 0.86 & 0.08 \\
\hline MNBrite & 0.67 & 0.35 \\
\hline M93-192 & 0.60 & 0.37 \\
\hline M95-1 & 0.59 & 0.15 \\
\hline M95-4 & 0.54 & 0.28 \\
\hline Chevron & 0.53 & 0.10 \\
\hline GD 2-27 & 0.46 & 0.07 \\
\hline M69 & 0.45 & 0.22 \\
\hline SI 4-36 & 0.43 & 0.17 \\
\hline Karl & 0.41 & 0.45 \\
\hline M95-7 & 0.40 & 0.55 \\
\hline SI 2-26 & 0.39 & 0.25 \\
\hline Foster & 0.38 & 0.22 \\
\hline Robust & 0.37 & 0.22 \\
\hline M94-1 & 0.32 & 0.24 \\
\hline M94-2 & 0.25 & 0.21 \\
\hline M79 & 0.20 & 0.09 \\
\hline SI 3-31 & 0.19 & 0.11 \\
\hline GD 2-18 & 0.14 & 0.13 \\
\hline $\mathrm{LSD}_{0.05}{ }^{\mathrm{b}}$ & 0.64 & 0.27 \\
\hline
\end{tabular}

a Barley cultivars or lines followed by an * indicate two-row barleys; those without a star indicate six-row barleys.

${ }^{b}$ Means of lines and cultivars were compared using Fishers' least significant differences test. 
capable of producing DON and 15-ADON in barley. As in previous experiments $(1,16)$, we utilized the rice cultures of our three isolates to verify whether or not the isolates of $F$. graminearum produce various trichothecene toxins in vitro. The method to detect and quantify DON and 15-ADON via single-kernel analyses was shown to be effective, as in a study by Mirocha et al. (17).

Previous investigations have shown that nutrients in growth media affect the in vitro production of trichothecenes by $F$. graminearum $(9,12)$. Other studies have found that spores sampled from several fungal species collected from various media contained mycotoxins either within or on the spore surfaces $(10,25,27)$. Our findings do not refute those earlier findings. Those studies were performed using different genera and species of fungi, and the methods used to produce the macroconidia of the three isolates of $F$. graminearum in our investigations were not comparable.

In the first greenhouse experiment, there were no detectable differences among the three isolates of $F$. graminearum for their ability to produce DON or $15-\mathrm{ADON}$ in Robust or Chevron. We found that DON and 15-ADON could be detected in inoculated spikelets of both cultivars as early as $48 \mathrm{~h}$ after inoculation. This suggests trichothecenes are produced much earlier than indicated by previous investigations, where DON was quantified 8 to 14 days PI $(13,14)$. Visible symptoms of infection, which appeared as water-soaked spots and chlorosis on lemmas of inoculated barley spikelets, were apparent at $48 \mathrm{~h}$ on both cultivars. At $72 \mathrm{~h}$, the inoculated spikelets showed evidence of chlorosis and some necrosis, but spikelets were still partly green. Spikelet necrosis (no green tissue visible) occurred between 72 and 120 h PI. Toxin accumulation increased dramatically following necrosis (Fig. 2). We performed analyses of variance using the concentration of DON and 15-ADON in inoculated spikelets of Robust and Chevron (data not shown) based on the kernel weights of the two cultivars and found differences between Robust and Chevron and among the three fungal isolates we studied. However, we felt these comparisons were misleading, as Robust and Chevron are drastically different in many agronomic traits, including mean kernel weight. Chevron was a selection of barley made from a lot of seed that was brought to the United States in 1914 from Zurich, Switzerland (23). Even then, Chevron was characterized as having thin kernels (low kernel weight). Robust was released in 1983 from the Minnesota barley breeding program for characteristics such as plump kernels (higher kernel weight due to volume) and other malting quality characteristics (21). Our comparisons were made using the yield of DON and 15-ADON obtained per inoculated spikelet ( $\mu \mathrm{g}$ per spikelet or $\mathrm{ng}$ per spikelet). The differences in kernel weight between Robust and Chevron did not affect detectable differences of yield of DON and 15-ADON synthesized by the three isolates of $F$. graminearum studied.

In the second greenhouse experiment, there were no detectable differences among the six lines and cultivars of barley that were tested for DON and 15-ADON accumulation. DON and 15-ADON were detected in inoculated spikelets of the six barley lines and cultivars as early as $36 \mathrm{~h}$ PI. At that time interval, small watersoaked spots were visible on lemmas of inoculated barley spikelets with no visible chlorosis. Spikelet chlorosis was evident at 54 and $72 \mathrm{~h}$ PI, and spikelet necrosis (tan to black spikelets) occurred between 72 and $90 \mathrm{~h}$ PI on all lines and cultivars. DON and $15-\mathrm{ADON}$ were detected $12 \mathrm{~h}$ earlier in the second greenhouse experiment than in the first greenhouse experiment. To our knowledge, this is the earliest detection of these toxins in the infection processes of $F$. graminearum reported in barley. Establishing when DON and/or 15-ADON are synthesized facilitates studying the effects of promising fungicides, biocontrol organisms, new resistant sources of germ plasm, or novel genetic resistance mechanisms that may prevent or delay the biosynthesis of these toxins.

There was a high degree of variability among the replicates for the yield of DON and 15-ADON among the $F$. graminearum isolates in the first greenhouse experiment and among the six lines and cultivars in the second greenhouse experiment. Increasing the number of replicates or the number of lines and cultivars would increase the precision of the experiment, and justified our use of 31 lines and cultivars in the third greenhouse experiment. Several interaction components were significant in the first greenhouse experiment, although their magnitude was small relative to the main effect of time intervals. The primary objective of the time interval experiments was not to determine the rate of toxin accumulation but rather to determine when DON and 15-ADON could be detected; thus we used analyses of variance in the first and second greenhouse experiments. We conducted regression analyses (data not shown); however, the response surfaces were linear in one instance and nonlinear in another. Data obtained from the measurement of other independent variables such as temperature, light intensity and duration, and host plant water relations during the development of the FHB infection may improve the ability to characterize DON and 15-ADON accumulation. We did not measure other independent variables since our objective was to characterize when we could first detect the two toxins in inoculated barley spikelets.

In the third greenhouse experiment, large differences of DON yield among the lines and cultivars were observed. Steptoe (FHB-susceptible) had the highest accumulation of DON at $1.24 \mu \mathrm{g}$ per spikelet compared with the line GD 2-18 (moderately resistant to FHB [6]), which had only $0.14 \mu \mathrm{g}$ per spikelet. We found no clear relation between DON and 15-ADON yield of inoculated spikelets among the 31 lines and cultivars tested. Several of the 31 lines and cultivars that had the highest yield of DON per inoculated spikelet were reported by Capettini (6) to possess higher levels of resistance to spread of FHB in point-inoculated heads (type-2 resistance) (22), particularly the two-row cultivars Svanhals and Fredrickson. Capettini (6) inoculated barley using the same techniques we used and observed that the mean numbers of kernels, at 21 days PI, to which the pathogen spread in heads of cultivars Svanhals and Fredrickson were 2.4 and 2.6, respectively. He also observed that the line GD 2-18 had a mean of 6.7 infected kernels. In our experiment, cultivars Svanhals and Fredrickson had means of 1.17 and $1.02 \mu \mathrm{g}$ of DON per inoculated spikelet, respectively (Table 4). In comparison, GD 2-18 had a mean of $0.14 \mu \mathrm{g}$ of DON per inoculated spikelet. The two studies suggest that different genetic mechanisms affect resistance to spread of FHB in barley heads and toxin accumulation and degradation (13). Future studies could investigate how these different barleys inhibit DON production or degrade DON (11). Single-kernel analyses for DON and 15-ADON yield and point-inoculations of heads might be utilized in breeding populations to identify markers for resistance to DON accumulation in combination with markers for resistance to spread of FHB in heads of barley, as has been done in wheat (4).

\section{ACKNOWLEDGMENTS}

We thank Henryk Jelen, Elaine Kolaczkowski, the late Yu Hui, and Amar Elakkad for their assistance conducting this research. We thank Neil Anderson for critical review of this manuscript. Support of this work by the American Malting Barley Association is gratefully acknowledged.

\section{LITERATURE CITED}

1. Abbas, H. K., Mirocha, C. J., and Shier, W. T. 1984. Mycotoxins produced from fungi isolated from foodstuffs and soil: Comparison of toxicity in fibroblasts and rat feeding tests. Appl. Environ. Microbiol. 48:654-661.

2. Adams, G. C., and Hart, L. P. 1989. The role of deoxynivalenol and 15-acetyldeoxynivalenol in pathogenesis by Gibberella zeae, as elucidated through protoplast fusions between toxigenic and nontoxigenic strains. Phytopathology 79:404-408.

3. Atanassov, Z., Nakamura, C., Mori, N., Kaneda, C., Kato, H., Jin, Y.-Z., Yoshizawa, T., and Murai, K. 1994. Mycotoxin production and pathogenicity of Fusarium species and wheat resistance to Fusarium head blight. Can. J. Bot. 72:161-167.

4. Bai, G.-H., Kolb, F. L., Shaner, G., and Domier, L. L. 1999. Amplified fragment polymorphism markers linked to a major quantitative trait locus controlling scab resistance in 
wheat. Phytopathology 89:343-348.

5. Burgess, L. W., Summerell, B. A., Bullock, S., Gott, K. P., and Backhouse, D. 1994. Laboratory Manual for Fusarium Research. 3rd ed. University of Sydney, Sydney, Australia.

6. Capettini, F. 1999. Inheritance of resistance to fusarium head blight in barley. Ph.D. thesis. University of Minnesota, St. Paul, MN.

7. Desjardins, A. E., Proctor, R. H., Bai, G., McCormick, S. P., Shaner, G., Buechley, G., and Hohn, T. M. 1996. Reduced virulence of trichothecene-nonproducing mutants of Gibberella zeae in wheat field tests. Mol. PlantMicrobe Interact. 9:775-781.

8. Evans, C. K., Hunger, R. M., and Siegerist, W. C. 1993. Enhanced production of Pyrenophora tritici-repentis conidial suspensions. Plant Dis. 77:981-984.

9. Greenhalgh, R., Neish, G. A., and Miller, J. D. 1983. Deoxynivalenol, acetyldeoxynivalenol, and zearalenone formation by Canadian isolates of Fusarium graminearum on solid substrates. Appl. Environ. Microbiol. 46:625629.

10. Land, C. J., Lundström, H., and Werner, S. 1993. Production of tremorgenic mycotoxins by isolates of Aspergillus fumigatus from sawmills in Sweden. Mycopathologia 124:8793.

11. Miller, J. D., and Arnison, P. G. 1986. Degradation of deoxynivalenol by suspension cultures of the fusarium head blight resistant wheat cultivar Frontana. Can. J. Plant Pathol. $8: 147-150$.

12. Miller, J. D., Taylor, A., and Greenhalgh, R. 1983. Production of deoxynivalenol and related compounds in liquid culture by
Fusarium graminearum. Can. J. Microbiol. 29:1171-1178

13. Miller, J. D., and Young, J. C. 1985. Deoxynivalenol in an experimental Fusarium graminearum infection of wheat. Can. J. Plant Pathol. 7:132-134.

14. Miller, J. D., Young, J. C., and Trenholm, H. L. 1983. Fusarium toxins in field corn. I. Time course of fungal growth and production of deoxynivalenol and other mycotoxins. Can. J. Bot. 61:3080-3087.

15. Mills, J. T. 1982. Development of fusaria and fusariotoxins on cereal grains in storage. Can. J. Plant Pathol. 4:217-218.

16. Mirocha, C. J., Abbas, H. K., Windels, C. E., and Xie, W. 1989. Variation in deoxynivalenol, 15-deoxynivalenol, 3-acetyldeoxynivalenol, and zearalenone production by Fusarium graminearum isolates. Appl. Environ. Microbiol. 55:1315-1316.

17. Mirocha, C. J., Kolaczkowski, E., Xie, W., Yu, H., and Jelen, H. 1998. Analysis of deoxynivalenol and its derivatives (batch and single kernel) using gas chromatography/mass spectrometry. J. Agric. Food Chem. 46:14141418.

18. Mirocha, C. J., Xie, W., Xu, Y., Wilcoxson, R. D., Woodward, R. P., Etebarian, R. H., and Bekele, G. 1994. Production of trichothecene mycotoxins by Fusarium graminearum and Fusarium culmorum on barley and wheat. Mycopathologia 128:19-23.

19. Nelson, P. E., Toussoun, T. A., and Marasas, W. F. O. 1983. Fusarium species: An Illustrated Manual for Identification. Pennsylvania State University, University Park.

20. Parry, D. W., Jenkinson, P., and McLeod, L. 1995. Fusarium ear blight (scab) in small grain cereals - a review. Plant Pathol. 44:207238.

21. Rasmusson, D. C., and Wilcoxson, R. W. 1983. Registration of Robust barley. Crop Sci. 23:1216.

22. Schroeder, H. W., and Christensen, J. J. 1963 Factors affecting resistance of wheat to scab caused by Gibberella zeae. Phytopathology 53:831-838.

23. Shands, R. G. 1939. Chevron, a barley variety resistant to stem rust and other diseases. Phytopathology 29:209-211.

24. Sinha, R. C., and Savard, M. E. 1997. Concentration of deoxynivalenol in single kernels and various tissues of wheat heads. Can. J. Plant Pathol. 19:8-12.

25. Sorenson, W. G., Frazier, D. G., Jarvis, B. B., Simpson, J., and Robinson, V. A. 1987. Trichothecene mycotoxins in aerosolized conidia of Stachybotrys atra. Appl. Environ. Microbiol. 53:1370-1375.

26. Wang, Y. Z., and Miller, J. D. 1988. Effects of Fusarium graminearum metabolites on wheat tissue in relation to Fusarium head blight resistance. J. Phytopathol. 122:118-125.

27. Wicklow, D. T., and Shotwell, O. L. 1983. Intrafungal distribution of aflatoxins among conidia and sclerotia of Aspergillus flavus and Aspergillus parasiticus. Can. J. Microbiol. 29:1-5.

28. Wilcoxson, R. D., Kommedahl, T., Ozmon, E A., and Windels, C. E. 1988. Occurrence of Fusarium species in scabby wheat from Minnesota and their pathogenicity to wheat. Phytopathology 78:586-589.

29. Zadoks, J. C., Chang, T. T., and Konzak, C. F. 1974. A decimal code for the growth stages of cereals. Weed Res. 14:415-421. 